\title{
A PRESSURE LIMITING VALVE FOR ANAESTHETIC AND RESPIRATOR CIRCUITS
}

\author{
H.T. NORAY, M.D., C.H.C.P.(C) ${ }^{*}$
}

IT IS AMAZING that almost three-hundred years after the first safety valve was put on a steam pressure vessel, a safety valve is not yet required on the breathing circuit connected to a patient's lungs.

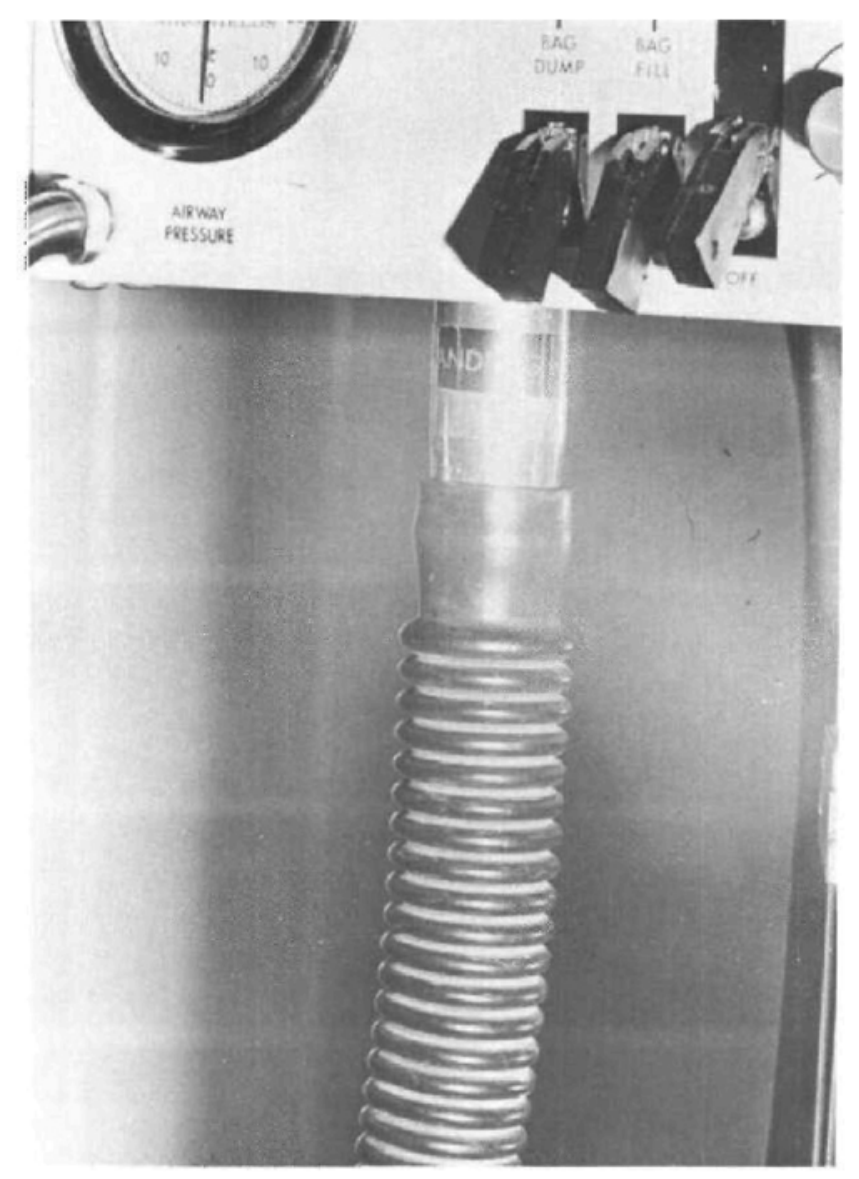

Figure 1. Air Shields ventimeter-ventilation; Breathing circuit attachment connected to bag mount.

-Department of Anaesthesia, University of Western Ontario and St. Joseph's Hospital, London, Canada.

Canad. Anaesth. Sac. J., vol. 19, no. 5, September 1972 
High pressure can develop in a closed breathing circuit when expiratory valves stick shut, are closed more tightly than intended, when flush valves are left on or held open by accidental pressure from apparatus or visitors. The exhalation valves of certain types of non-rebreathing valves used in open circuit methods of anaesthesia may stick shut in the closed position. With continued gas flow, dangerously high pressures soon develop.

With mechanical ventilation, inadvertent attachment of the respirator hose to the respirator bag mount (Figures 1, 2, and 3) excludes the bellows from the circuit, and with the expiratory valve closed, the patient's langs are exposed to pro-

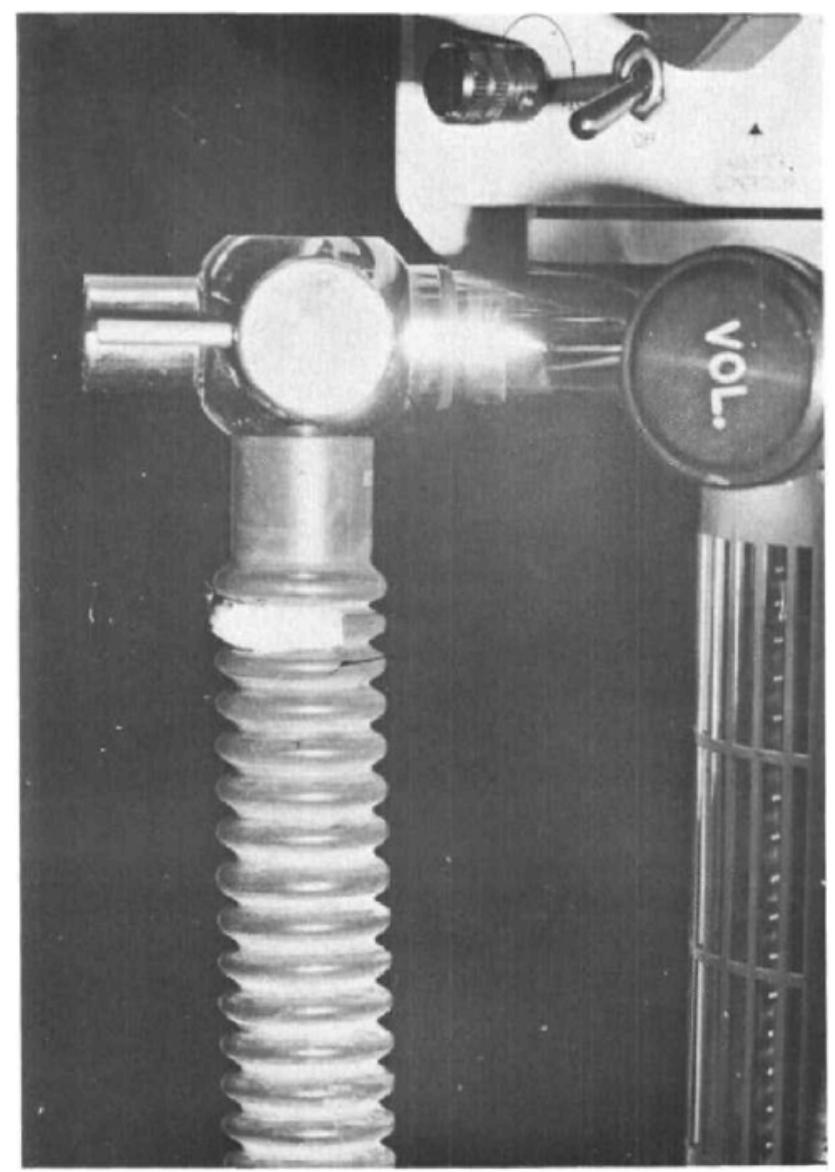

Ficure 2. Ohio operating room ventilator: Stopcock in incorrect position.

gressive distention by gas inflow from the anaesthetic machine with only the non-compliant corrugated tubing of the circle absorber intervening. Depending on the rate of gas inflow, dangerously high pressures soon develop, leading to pulmonary rupture, mediastinal emphysema and tension pneumothorax. This ac- 


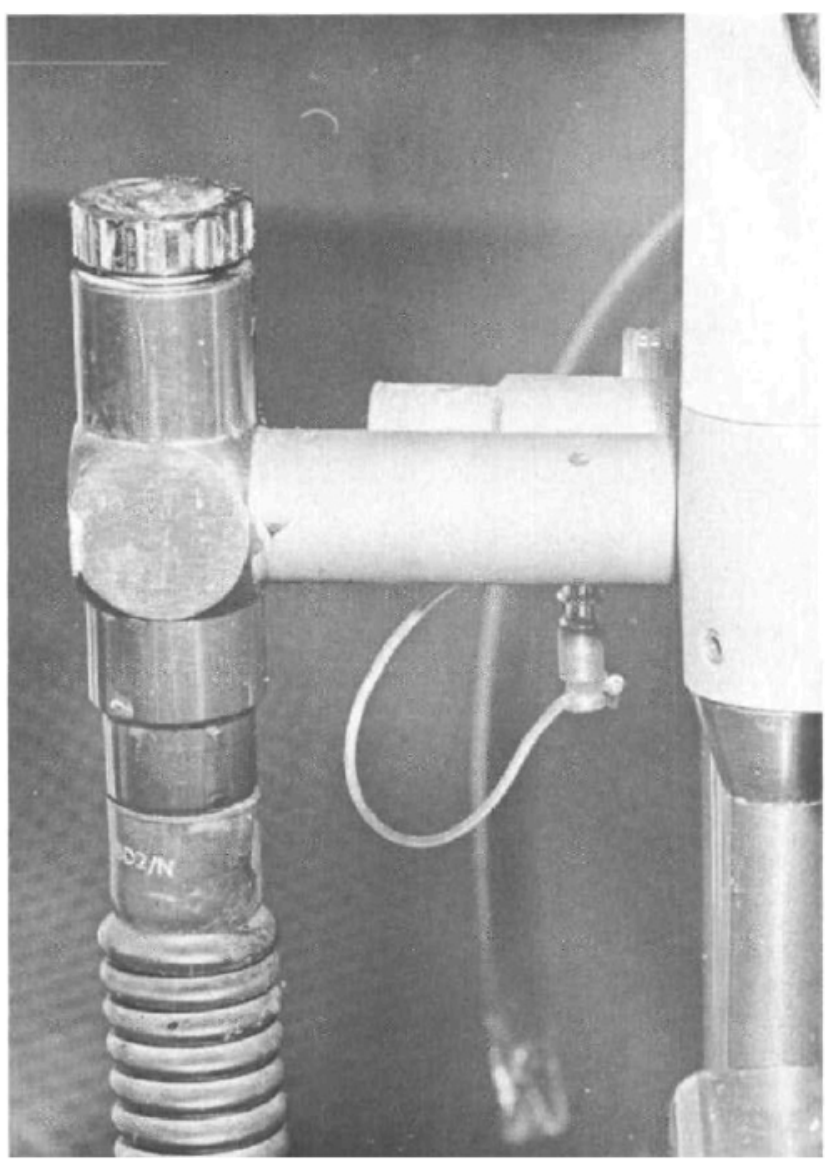

FIgure 3. Bird Mark IV ventilator: Breathing circuit connected to bag mount.

cident has occurred with the Bird Mark IV respirator, the ventimeter-ventilator (Air Shields) and the Ohio operating room ventilator and has been reported to me in personal conversation by colleagues. It would appear that such accidents are more frequent than is apparent from the literature. The risks of these mechanical and human errors can be removed by the incorporation of a safety valve which limits the pressure attainable in the patient's breathing circuit.

A simple valve has been developed which is designed to limit the pressure to 40 torr, and can be attached to any anaesthetic machine. The valve consists of a steel ball with an attached weight resting on a machined-valve seat as shown diagrammatically in Figure 4. The housing of this safety limiting valve is constructed of plated brass; it is compact (Figure 5), easy to clean and practically indestructible. The details of the steel ball and the attached weight are shown in Figure 6. The opening pressure is determined by the weight which can be varied if different opening pressures are desired. 


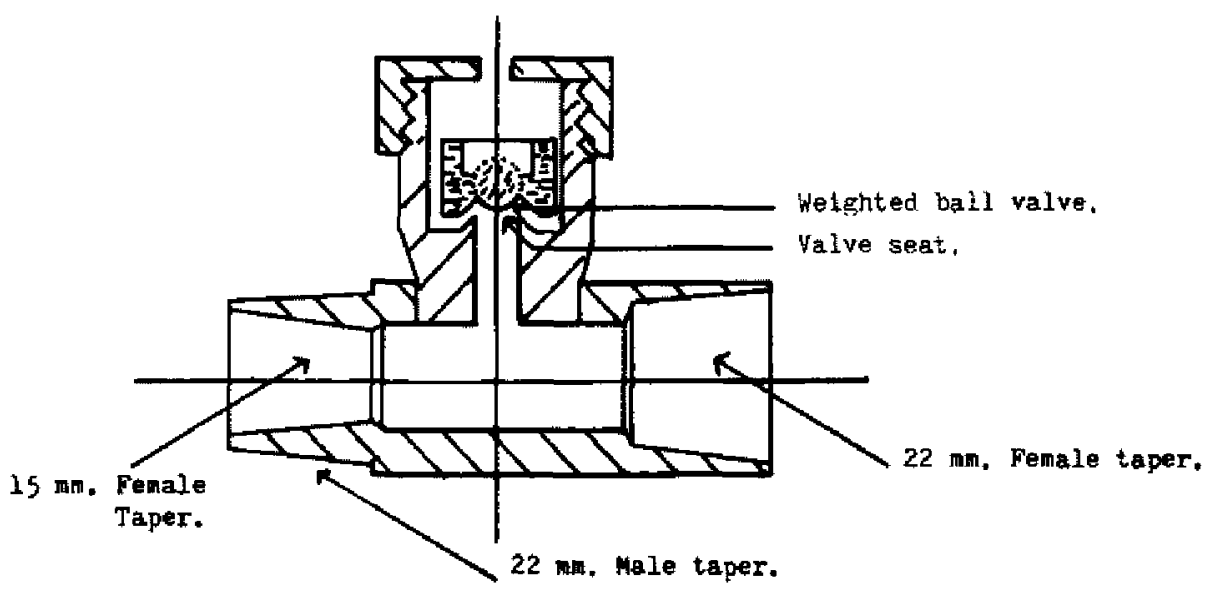

Pressure rellef valve for anaesthet1c machines.

Not to exact scale.

Approx. 1 : 1 .

H.T.N.

Figure 4. Schematic diagram of pressure limiting valve.

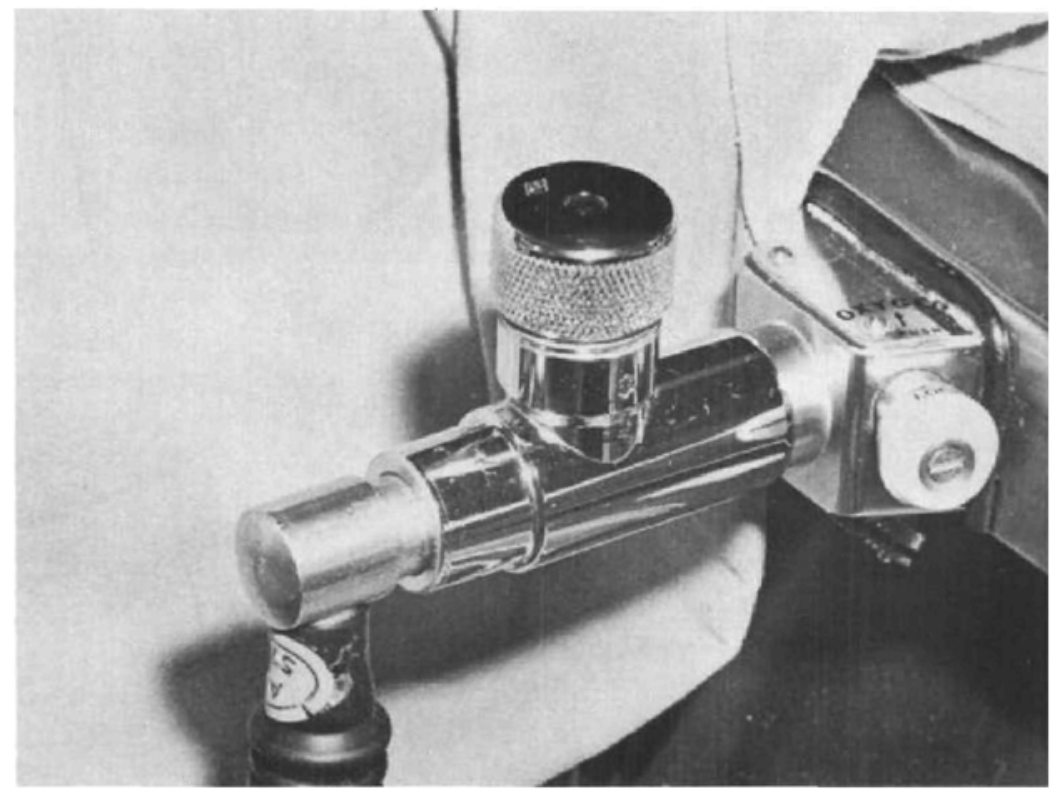

Frgure 5. Pressure limiting valve situated at gas outlet to breathing circuit. 


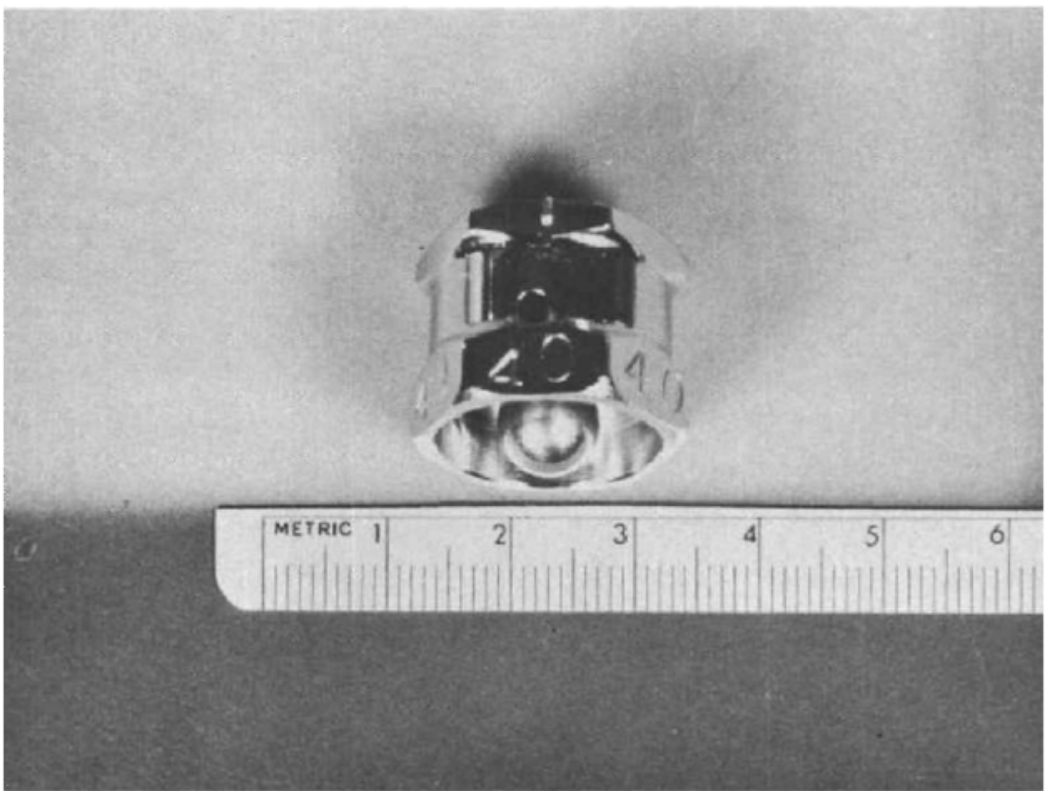

Ficure 6. Detail of valve.

When the predetermined pressure is reached inside the breathing circuit, the ball is lifted allowing excess gas to escape through an exhaust port. In order to function properly, the valve must be placed in a vertical position. Absence of leaks can be confirmed by placing about $2 \mathrm{ml}$ of water into the exhaust port. When the predetermined pressure is exceeded, the valve produces a chattering sound alerting the anaesthetist's attention to the high pressure on the breathing circuit.

The valve shown is designed to be incorporated into the breathing circuit or at the outlet port from the machine to the breathing circuit as shown in Figure 5. The design can be easily modified for permanent installation into the line supplying gases to the breathing circuit.

The described pressure limiting valve is presently incorporated in all anaesthetic machines in our hospital and the pressure limit of 40 torr has proven satisfactory in our practice. Tests have shown that it can effectively remove the hazard of a dangerously high pressure developing inside the patient breathing circuit. It is recommended that this simple safety device should be incorporated as standard equipment in all anaesthetic gas machines.

\section{SUMMARY}

A simple pressure limiting valve is described which can be adapted to-any anaesthetic machine and which effectively prevents the development of danger- 
ously high pressures in the breathing circuits attached to the patient's airway. Such a safety valve should be incorporated as standard equipment into all anaesthetic machines.

\section{RÉSUMÉ}

Nous avons décrit une valve simple destinée à limiter la pression dans le circuit respiratoire existant entre le malade et l'appareil à anesthésie.

Cette valve peut s'adapter à tout genre d'appareil et elle prévient la formation de pressions dangereusement élevés.

Une telle valve devrait faire partie de l'équipement standard de tout appareil servant à administrer l'anesthésie.

\section{ACKNOWLEDGMENTS}

I wish to express my appreciation to Mr. George Redrup of the Medical Industrial Equipment (Canada) Limited, 6525 Stanley Avenue, Niagara Falls, Ontario by whom the valve was manufactured. 